of lysophosphatidylcholine the remaining particulate material was rapidly fixed in glutaraldehyde. Electron microscopy indicates that the two phases of the solubilization process involve a structural transition of the myelin membrane.

Gent, W. L. G., Gregson, N. A., Gammack, D. B. \& Raper, J. H. (1964). Nature, Lond., 204, 553.

Gregson, N. A., Kennedy, M. \& Leibowitz, S. (1971). Immunology (in the Press).

\section{Amino Acid Sequence of the Basic Protein of Human Brain Myelin}

By P. R. Carnegre. (Russell Grimwade School of Biochemistry, University of Melbourne, Melbourne, Vic. 3052, Australia)

The central nervous system contains an unusual basic protein that comprises $30 \%$ of the total protein in myelin (Eng, Chao, Gerstl, Pratt \& Tavaststjerna, 1968). The sequence of the 170 amino acids in the protein has been determined (Carnegie, 1971). Micro-heterogeneity occurs in the protein as a result of methylation of a single arginine residue. A cytoplasmic enzyme from brain transfers methyl groups to arginine-107 with the formation of $\omega-N$-monomethyl- and $\omega-N N^{\prime}$ dimethyl-arginine (Baldwin \& Carnegie 1971). This methylated arginine occurs adjacent to a non-polar region in the molecule that has been isolated and shown to induce an autoimmune attack by lymphocytes on the central nervous system (Lennon, Wilks \& Carnegie, 1970).

The basic protein has been shown to be present in the intraperiod line in the lamellar structure of myelin (Dickinson, Jones, Aparicio \& Lumsden, 1970). As the protein has numerous aspartic acid, histidine and serine residues interspersed along the molecule it is speculated that in the non-polar environment within myelin they may be participating in a 'charge-relay system' (cf. Blow, Birktoft \& Hartley, 1969). Fernandez-Moran (1959) has suggested that membranes with a lamellar structure may be functioning as semi-conductors.

Baldwin, G. S. \& Carnegie, P. R. (1971). Science, N.Y. (in the Press).

Blow, D. M., Birktoft, J. J. \& Hartley, B. S. (1969). Nature, Lond., 221, 337.

Carnegie, P. R. (1971). Nature, Lond. 229, 25.

Dickinson, J. P., Jones, K. M., Aparicio, S. R. \& Lumsden, C. E. (1970). Nature, Lond., 227, 1133.

Eng, L. F., Chao, F. C., Gerstl, B., Pratt, D. \& Tavaststjerna, M. G. (1968). Biochemistry, Easton, 7, 4455.

Fernandez-Moran, H. (1959). In Biophysical Science-A Study Program, p. 319. Ed. by Oncley, J. L. New York: John Wiley and Sons Inc.

Lennon, V. A., Wilks, A. V. \& Carnegie, P. R. (1970). J. Immun. 105, 1223.

\section{Trypan Blue: Reaction with Myelin}

By J. P. Dickinson and S. G. R. Aparicio. [Department of Pathology (Research), School of Medicine, University of Leeds, Leeds LS2 9NL,U.K.]

A simpler and more sensitive method for estimating the basic encephalitogenic protein of myelin in myelin fractions than is afforded by conventional extraction and ion-exchange purification techniques was required. It had been claimed (Adams \& Bayliss, 1968) that the tetra-azo-tetrasulphonic acid dye, Trypan Blue, in certain conditions combines specifically with this protein and with the nucleohistones in frozen sections of centralnervous-system tissue. Reaction of central-nervoussystem myelin, purified in the ultracentrifuge and dissolved in dry chloroform-methanol $(2: 1, \mathrm{v} / \mathrm{v})$, with the dye dissolved in methanol (to give chloroform-methanol, $1: 1, \mathrm{v} / \mathrm{v}$, final composition) leads to a precipitate, which, after the washing away of excess of dye, is dissolved in $0.1 \mathrm{M}$-sodium dodecyl sulphate solution, and the precipitated dye is determined from the extinction at $585 \mathrm{~nm}$. The method satisfies criteria for quantitative use.

Different myelin preparations have different capacities for reacting with the dye: correlation plots with all lipid components show, as expected, weak negative regressions. Only plots against total nitrogen and total protein show strong positive regressions, and only that against protein gives a regression line that has an intereept not significantly different from zero $(0.7>P>0.6)$ as well as a strong correlation $(P<0.001)$. [Total protein was determined by the method of Lowry, Rosebrough, Farr \& Randall (1951) on solutions of myelin in $0.1 \mathrm{M}$ sodium dodecyl sulphate; the values obtained are always equal to, or greater than, those obtained after alkali digestion with or without prior lipid extraction, presumably owing to reduced handling losses and degradation.]

The weight fraction of myelin precipitated with dye is very similar to the total protein content, and the amino acid compositions of the precipitate and the parent myelin are closely similar, even though these may differ considerably for different myelins. The sum of the uncorrected amino acid residue weights accounts for more than $90 \%$ of the non-dye part of the precipitates.

Thus, in these restricted conditions, Trypan Blue combines with all proteins and not specifically with basic protein, and the dye-combining power in dry organic solvents may be used as a measure of protein content in proteolipids (that is protein and lipid complexes soluble in chloroform-methanol, $2: 1, \mathrm{v} / \mathrm{v})$. The method is reproducible, readily standardized and has a slightly greater sensitivity ( $E$ units/mg of protein per test) than the standard method of Lowry et al. (1951). 
When water is introduced to the dye-myelin system the situation becomes more complex. The amount of dye remaining insoluble when the previously prepared precipitates are washed with chloroform-methanol-water (1:4:5, by vol.) is decreased to about half. Preliminary experiments indicate that in these conditions, and when freshly prepared myelin is treated with Trypan Blue in purely aqueous buffer (0.1 M-acetate, pH5.0, the conditions used for histological staining), a fraction of the protein is released into the aqueous medium. It is likely that this protein is a particular molecular species.

Adams, C. W. M. \& Bayliss, O. B. (1968). J. Histochem. Cytochem. 16, 110.

Lowry, O. H., Rosebrough, N. J., Farr, A. L. \& Randall, R. J. (1951). J. biol. Chem. 193, 265.

\section{Proteins of the Plasma Membrane Lining the Lumen of the Rat Bladder}

By B. KetTerer and R. MARIAN Hicks. (Courtauld Institute of Biochemistry and Bland Sutton Institute of Pathology, The Middlesex Hospital Medical School, London W1P $5 P R, U . K$.

Rat transitional epithelium acts as a barrier to the flow of water between the underlying tissue fluids and the hyperosmotic urine of the bladder. The maintenance of this permeability barrier appears to depend on the luminal plasma membrane (Hicks, 1966). This membrane, when fixed and sectioned for electron microscopy, appears to be asymmetrically thickened in transverse section (Hicks, 1965) and to have a subunit structure in tangential section. Negative-contrast staining of this membrane again indicates that it is composed of subunits and that these subunits are arranged in a hexagonal lattice (Hicks \& Ketterer, 1969). When suitable images obtained from negativecontrast stained material are subjected to optical diffractometry it is found that the hexagonal subunits can be resolved into dodecamers composed of subunits of equal diameter, suggesting that they represent spheres approx. $30 \AA$ in diameter (Warren \& Hicks, 1970).

The bladder luminal membrane has been separated from homogenates of bladder epithelium by centrifugation through sucrose density gradients (Hicks \& Ketterer, 1970). Owing to the fact that it can occur either as a membrane limiting the cell surface or as intracellular fusiform vesicles, thickened membrane occurs in several fractions. The various fractions have been analysed for lipids and amino acid content. The fraction of greatest purity is unusual in having a higher-than-average proline content (Hicks, Ketterer \& Beale, 1969).

The protein content of this fraction has now been analysed by polyacrylamide-gel electrophoresis in an $8 \mathrm{~m} \mu$ urea-sodium dodecyl sulphate medium containing a mercaptan. At least 12 polypeptide components have been observed, ranging in molecular weight from 10000 to 100000 , with most of the material greater than 20000 in molecular weight.

If the particles making up the dodecameric subunits were spherical proteins they might be expected to have a molecular weight of approx. 10000; however, the protein analysis does not suggest that sufficient protein of this molecular weight is present to account for these spheres. If the interaction of protein molecules with sodium dodecyl sulphate can be taken as a model then it is more likely that the proteins in membranes are extended polypeptides rather than globular in shape (Reynolds \& Tanford, 1970).

This work was made possible by a generous grant from the Cancer Research Campaign.

Hicks, R. M. (1965). J. Cell Biol. 26, 25.

Hicks, R. M. (1966). J. Cell Biol. 28, 21.

Hicks, R. M. \& Ketterer, B. (1969). Nature, Lond., 224, 1304.

Hicks, R. M. \& Ketterer, B. (1970). J. Cell Biol. 45, 542. Hicks, R. M., Ketterer, B. \& Beale, D. (1968). Biochem. $J .109,41$ P.

Reynolds, J. A. \& Tanford, C. (1970). J. biol. Chem. 245, 5161.

Warren, R. C. \& Hicks, R. M. (1970). Nature, Lond., 227, 5255.

The Identification of the Site of Action of Dicyclohexylcarbodi-imide as a Proteolipid in Mitochondrial Membranes

By K. J. Cattell, C. R. Lindop, I. G. Knight and R. B. BeEChey. (Shell Research Ltd., Woodstock Agricultural Research Centre, Sittingbourne, Kent, U.K.)

The mode of action of dicyclohexylcarbodi-imide as an inhibitor of mitochondrial oxidative phosphorylation suggests that it reacts specifically and covalently with a membrane component that is essential for energy-conservation reactions (Beechey, Roberton, Holloway \& Knight, 1967).

We have presented evidence that a significant proportion of the radioactivity of $\left[{ }^{14} \mathrm{C}\right]$ dicyclohexylcarbodi-imide-treated mitochondrial membranes is bound to a chloroform-methanol-soluble protein fraction, i.e. proteolipid (Cattell, Knight, Lindop \& Beechey, 1970). Here we show that the radioactivity is associated with a single proteolipid. By 